\title{
The Function and Developing Direction of the Current Chinese Stock Duty
}

\author{
Yawei Zhang ${ }^{1}$ \\ ${ }^{1}$ Ph.D. Candidate, School of Civil, Commercial \& Economic Law, China University of Political Science and \\ Law, Beijing, China \\ Correspondence: Yawei Zhang, Ph.D. Candidate, School of Civil, Commercial \& Economic Law, China \\ University of Political Science and Law, Beijing, China. E-mail: zhangyawei_cupl@163.com
}

Received: June 11, 2015 Accepted: July 6, 2015 Online Published: July 30, 2015

doi:10.5539/ijms.v7n4p145 URL: http://dx.doi.org/10.5539/ijms.v7n4p145

\begin{abstract}
Two vital problems of the current Chinese stamp duty are whether the stamp duty legal system should be abolished and what would be its future role and current function in the Chinese stock markets. The present stamp duty which implemented in the Stock system has the drawbacks in legislation and naming, what would also challenge the current system is the co-exchange system in stock market among Hongkong and Shanghai started not long ago in 2014. However, due to the structure of the Chinese stock market, the stamp duty system are suggested to be hold, but it need to be revised in its tax base, legislation mode and also the nominating structure.
\end{abstract}

Keywords: Chinese stock exchange tax, stamp duty, Shanghai-Hong Kong Stock Connect program, tax legal prescription

\section{The Background and the Problems}

The stock duty is a type of circulation tax collected on stock exchange activities. As one of the three most vital stock market taxationcategories, it plays a decisive role in the contemporary market. The stock duty is the most important tax category in Chinese stock market, which was levied since 1990. However, the collection of the stock duty in China has accompanied many arguments since its enaction. Until now, the Chinese stock market experienced about 20 years' speedy development and converted from a under-developed market to the second largest stock market in the world with the total market value of more than $\$ 4500$ bn. However, with the development of the market value, many new financial innovation products and trading mechanisms has been created and generalized. From the margin trading, start-up board, small and medium-sized board, the three board, to the current co-exchange system in stock market among Hongkong and Shanghai, the Chinese stock market has gradually adapt itself to the most advanced stock market in the world. Nonetheless, in contrast with the amazing development of the stock market, the legal mechanism of the Chinese stock market remains comparatively unchanged in these two decades. Whether it is reasonable to continue the present stock duty legal system, and which function and developing direction should the Chinese stock duty have are now the most vital problems of the current academic circle. However, among the Chinese legislation circle, academic and practical field, there has still exist big controversy about the formal problems. And these divergences are always put aside and beneglected, which in return hindered the development of the market to some extent. Therefore, it is required to combine the formal problems to research in the stock exchange tax system and try to draw the outline of the future reformation.

\section{The Challenge of the Chinese Stock Exchange Tax System}

\subsection{The Stock Duty System}

As the traditional partition, the tax collected on stock market around the world can be generally divided into four categories. The first type is the tax for IPO, such as the registration tax on stock and debt market in Ireland and England. The second type is the tax on stock exchange, which belongs to the circulation tax. The income tax levied on the stock exchange income is the third category of stock market tax, which includes tax for the stock interest income and thetaxation on the capital gains of the exchange. The last kind should be the property tax on stock, such as the gift tax or the legacy duty.

The taxation focus by this article would be the second type, which is the specific circulation tax collected on 
personal or institutional stock exchange act. The origin of the stock duty could be traced back to 1694 in England, which was the stamp duty collected by the UK government in the London stock exchange bourse.The earlier stock transaction tax theory should belong to the theory of levying certain taxes on stock transaction put forward by famous British economist Keynes in his work The General Theory of Employment, Interest and Money after the great depression in 1936. Keynes believed that such tax can control the excessive speculation behavior of financial traders with no information while increasing speculation cost, so as to finally reach the objective of guiding investment to real economic production sectors and decrease economic fluctuations. Among the countries that still keep stock transaction tax, most of them set lower tax rate. Relative to its financial income function, the macro control function of stock transaction tax is generally more and more paid attention to. The practice of stock transaction tax is the implementation of securities stamp tax system. Although literally stamp tax should not belong to stock transaction tax, but in terms of China's current system, there is no difference between stock stamp tax and stock transaction tax in taxpayer, tax base and taxation basis. Thus it can be deemed that stock transaction stamp tax levied by China at present is in essence one kind of stock transaction tax. However, as China just levies stock transaction stamp tax targeting at A and B share market, the stock stamp tax levied by China at present is one kind of stock transaction tax to a great extent.

As to whether China should continue to implement the prevailing stock stamp tax system, there mainly exist the following three problems. Firstly, whether there exist deficiencies in the formulation and adjustment of Chinese legal system on stamp tax. Secondly, whether stamp tax has the problem of unworthy of its name under no-paper transaction mechanism of secondary market. Thirdly, whether stock transaction tax in China can exert its due role in restraining market fluctuations, as well as its influence on market efficiency.

With regards to the first issue, China's Provisional Regulations on Stamp Tax has been implemented since Oct 1, 1998, but such regulation failed to make corresponding adjustment as per Legislation Law after it came into effect. In legislative power, it is contrary to the regulations of Legislation Law. More importantly, its successive tax rate adjustment was often conducted by Ministry of Finance via a paper of document, which obviously violated relevant regulations and rule of taxation by law of Legislation Law, and also seriously not in conformity with the concept of "rule by law" emphasized by China at present. As per the regulations of article 8 of Legislation Law, the matters concerning basic economic system and basic system on finance, taxation, customs, finance and foreign trade can only be regulated by law. The levying of stamp tax and its tax rate adjustment undoubtedly involves the basic system of taxation, and should be regulated by law or at least regulated by formal administrative law via authorized legislation, while not be meddled by a paper of document of Ministry of Finance or provisional regulations.

Currently under the background of generally implementing no-paper transaction in Chinese stock market, the transaction taxation on secondary stock market in China still adopts "stamp tax", such nomination indeed deserves deliberation. Stamp tax should be one act tax levied on the act of underwriting and accepting the vouchers with legal effect in economic activities, and it was paid via the form of pasting stamp on transaction vouchers originally. However, the stamp tax levied by China targeting at secondary stock market transaction is in essence, completely conducted under no-paper electronic transaction, thus the name of "stamp tax" seems to be in name only.

In the aspect of the macroscopic readjustment and control efficiency of the stamp tax, the current most powerful theoretical support of the waving restrain function of the stamp duty is which presented by the famous Nobel prize owner James Tobin in his Janeway speech in the Princeton University. At this speech, Tobin initially suggested to levy a currency transaction tax to financial transactions.Then, Tobin specifically analysis this type of tax in his book "The New Economics One Decade Older" in 1974.He thinks that due to the distinction of the fluctuation, compared with the financial market, the product market and the working market would respond less sensitively to the price signal. Therefore, after the speculation in the international capital market, it would finally lead to the distortion of the goods and labour service market and to some extent damage the whole welfare of the society.Apart from that, this tax could also restrain the short time speculation by improve its capitalized cost. And finally lower the flowability of the global capital market and maintain the stability of the financial market. And the part of academic circle who support to using the stamp duty as a unregulated policy for restraining speculation exchange and encouraging long term holding and value investment.

Seen from this point, market cannot allocate resources effectively. What's more, investors are not fully rational. The reason is that there are mainly two kinds of traders in the market. One is the "informed transaction party" who is of higher investment level and has sufficient information. And the other is "noise trader" who conducts transactions blindly with insufficient investment approach. The "informed transaction party" usually can hold the real market situation and conduct effective "value investment". On the contrary, the "noise trader" always 
follows the other traders frequently and goes after the rise and fall of the market due to the lack of real information and investment knowledge. In the market which is dominated by "noise traders", the security prices tend to fluctuate easily and "Herd Effect" will be formed easily. At the same time, stock transfer tax can effectively restrain the frequent non-rational transactions through increasing the cost of single transaction. And it encourages long-run holdings and value investment, which can greatly help stabilize the market and reduce non-rational market fluctuation. However, some opponents hold that the stock transfer tax can better restrict the opportunistic practices of "noise traders" only in the market where the "informed" professional investors are in the minority. In the market where the professional investors are in the majority, the stock transfer tax is inclined to make the price deviate from the stock value and then increase the price fluctuation because of the increased transaction cost instead of smoothingoutvolatility efficiently. In 2003, the third annual report of the International Monetary Fund Research Conference clearly pointed out, "Considering such elements as microstructure, assets pricing, rational expectation and international finance, we believe the stock transfer tax does not mean to "throw sands' to the wheels of financial market but 'pour sands' into the engine of the market. Therefore, our conclusion is that transaction tax has negative impact on price discovery, market fluctuation and market energy. And it leads to the reduction of the information efficiency of the stock market." The report of IMF also discovered that the stock transfer tax was not lowed because of the fluctuation brought by the "noise" transaction. Instead, it increased the frictional force of price discovery mechanism. There was no doubt that this conclusion denied the core effects of stock transfer tax. In the meanwhile, many researches of the domestic scholars deny the significant correlation of current stamp duty with the market fluctuation. Hereinto, the representatives are the statistical test adopted by Fan Nan and Wang Liping, the introduced GARCH (generalizedautoregressiveconditionalheteroskedasticity) model, the empirical research on the samples of the data in Shanghai and Shenzhen market (A share and B share) as well as the research method of stock turnover rate adopted by Guo Qi. The former empirical result indicated that the up-regulation of stamp duty would lead to the improvement of market return volatility and the down-regulation would lead to the reduction. For this reason, to reduce market volatility and the volatility of the revenue of noise traders, the government should further down-regulate the stamp duty rate so as to improve the market efficiency. Besides, the conclusion of the latter one has two sides: on one hand, the adjustment of the stamp duty rate has significant impact on the stock market volatility in a short period; on the other hand, in a long period, the down-regulation of the stamp duty rate in the stock transaction has no significant impact on the volatility of the A share market in Shanghai and Shenzhen.

\subsection{The New Challenges to Stock Stamp Duty Brought by Shanghai-Hong Kong Stock Connect Program}

In brief, Shanghai-Hong Kong Stock Connect Program means a connectivity mechanism. That is, Shanghai Stock Exchange and Hong Kong Stock Exchange allow the investors of Shanghai and Hong Kong to buy and sell the stock listed on the exchange of each other within the set range through the local stock company (or broker). In accordance with the current regulations, at the incipient stage of Shanghai-Hong Kong Stock Connect Program, the SH (Shanghai) Equities mean the constituent stocks of 180 index and 380 index as well as A+H share corporate stocks listed on Shanghai Stock Exchange. The HK (Hong Kong) Equities mean the constituent stocks with Hang Seng Composite Large-cap Index and Hang Seng Composite Middle-cap Index on Hong Kong Stock Exchange as well as $\mathrm{A}+\mathrm{H}$ share corporate stocks listed on both Hong Kong Stock Exchange and Shanghai Stock Exchange. In addition, Shanghai and Hong Kong can adjust the range of the investment according to the thepilotsituation.

As for the tax arrangement of "Shanghai-Hong Kong Stock Connect Program", it involves incomes tax and transaction tax. First of all, for capital gains, Mainland individual investors will not be charged individual income tax aiming at the gains resulted from transfer spread of the stocks listed on Hong Kong Stock Exchange through Shanghai-Hong Kong Stock Connect Program from November 17, 2014 to November 16, 2017. And for the gains resulted from the transfer spread of the stocks listed on Hong Kong Stock Exchange which Mainland business investors get through Shanghai-Hong Kong Stock Connect Program, they will be added to the total income and be charged corporate income tax according to laws. And in terms of dividend got by Mainland individual investors in the $\mathrm{H}$ shares listed on Hong Kong Stock Exchange through that program, $\mathrm{H}$ share corporate should apply to China Stocks Depository and Clearing Company Limited (hereinafter referred to as China Clearing). And China Clearing provides the list of Mainland individual investors for $\mathrm{H}$ Share Corporation which will withhold individual income tax at the rate of $20 \%$. And as for the dividend got by Mainland individual investors in the non-H Share listed on Hong Kong Stock Exchange through that program, China Clearing shall withhold individual income tax at the rate of $20 \%$. If the withholding tax has been charged abroad, individual investors can hold valid tax credit document and apply to the competenttaxauthorities of China Clearing for tax credit. As for the dividend got from the stocks listed on Hong Kong Stock Exchange invested 
through this program by Mainland equity investment fund, the individual income tax shall be charged according to the regulation mentioned above. Additionally, the dividend got from the stock listed on Hong Kong Stock Exchange invested through this program by Mainland business investors will be added to the total income and be charged corporate income tax according to laws. Hereinto, the dividend income got from the H Share which Mainland resident enterprise has held for 12consecutivemonths will be exempted from corporateincome tax in accordance with the law. Besides, the H Share Corporation listed on Hong Kong Stock Exchange should apply to China Clearing. And China Clearing shall offer the list of Mainland business investors to H Share Corporation. The Mainland business investors will not be charged dividend income tax by H Share Corporation. Instead, the enterprise should file a return andpay the tax. The mainland business investors can apply for tax according to the law when they pay the corporate income tax, if the listed corporation of non-H Share on Hong Kong Stock Exchange has withheld the dividend income tax. In terms of the stamp duty of the stock transaction in which mainland investors and Hong Kong market investors transfer stocks through this program, Hong Kong investors should pay stock transaction stamp duty according to the Mainland current tax system when they buy and sell, inherit and grant A Shares listed on Shanghai Stock Exchange through this program. Meanwhile, the mainland investors should pay the stamp duty according to the current tax system in Hong Kong Special Administrative Region when they buy and sell, inherit and grant Shares listed on Hong Kong Stock Exchange through this program.

When it comes to the possible challenges brought by Shanghai-Hong Kong Stock Connect Program to Chinese stock transactions, there is a case worth consideration. That is the stock transaction mechanism once conducted in Sweden. From 1984 to 1991, Sweden had charged stock transaction tax on financial market. In January 1984, Sweden officially charged stock transaction tax at the two-way rate of $1 \%$ towards the stock transactions. And in 1986, it brought share option into object of taxation and increased the two-way tax rate to $2 \%$. Either Swedish or foreign investors should be charged stock transaction tax as long as they select the stock trading agent registered in Sweden to trade the stock registered in Sweden. But the transactions between registered stock trading agents were not charged two-way tax at the rate of $1 \%$ until 1987.

Although the tax income of Swedish stock transaction had been increased from 1984 to 1989, its expected income still disappointed the outside world. The main reason causing this situation was the large amount of flight tax avoidance deal resulted from the defects of its tax system design. Even if the Swedish stocks were traded, the traders could avoid stock transaction tax easily as long as they did not select Swedish dealers, which provided great convenience for foreign investors to avoid taxes. Before the implementation of stock transaction tax, Swedish stocks were traded mainly on the stock exchanges in Stockholm, London and New York. However, after its implementation, many Swedish stock transactions were changed to other foreign markets. The reason was foreign investors could take the advantage of non-Swedish trading agents to conduct the transactions on London market so as to avoid the stock transaction tax in Swede easily and reduce the actual transaction cost.

The tax avoidances made the Swedish financial transaction tax system unable to result in good effects. For example, surrogate market was used to avoid taxes on stock market and derivatives were used to avoid taxes on fixed income stock market. At the beginning of 1991, Swede reduced the tax rate of stock transaction by half and then abolished all the stock transaction tax on December 1, 1991.Moreover, as a connectivity mechanism, Shanghai-Hong Kong Stock Connect Program may result in the similar negative impact with Sweden on the mainland stock transaction tax, because many large corporations selected to jointly issue $\mathrm{A}+\mathrm{H}$ shares. At present, the stock trading is connective only within a set range in Shanghai and Hong Kong, but the final purpose is to conduct full interworking transactions and promote the internationalization of RMB. Nonetheless, when the stocks of Shanghai and Hong Kong can be traded more widely, the transaction tax difference of two places is likely to stimulate the transaction behaviors which change markets to avoid taxes. The mass occurrence of such tax avoidance will not only affect the tax neutrality of stock transaction tax, but also lessen the functions of macroeconomic regulation and speculation refraining belonging to stock transaction tax.

\section{Functional Orientation of Stock Transaction Tax Legal System in China}

At present, the author holds that it is still necessary to implement stock transaction tax. At the same time, the functional orientation of such taxation should focus on refrain speculation to control the excessive transactions. Although numerous developed countries has cancelled stock transaction tax similar to the current stock stamp duty in succession, the major two features of Chinese stock market determine that we cannot copy the experience of other countries without considering our national conditions. On one hand, according to the statistics of "turnover rate" of the stock markets all over the world made by Credit Suisse Group AG in 2003, the turnover rate of Chinese stock market was close to $200 \%$, ranking the first in the world. It was twice as much as that in America and over four times in England. Such high turnover rate reflected the energy in Chinese short-term 
stock-market trades and the prevalence of speculation. On the other hand, the greatest difference of Chinese stock market with the other markets in developed countries is the proportion of the institutional investors. In China, small and medium investors take up $70 \%$ of the trading volume on stock market throughout the year. In other words, Chinese stock market usually cannot be dominated by institutional investors. And problem directly brought by the high proportion of small and medium investors was short-term transactions and prevalence of speculation. That is just one of the major reasons why Chinese turnover rate was abnormally high. On the stock markets of such developed countries as England and America, the institutional investors of mutual funds and hedge funds take up the majority of the transaction market. Different from private investors, institutional investors own investment approach and resolving ability of high level. And they have clear investment plan. Compared with private investors, they are unlikely to have excessive panic selling or frequent speculative trading. On this occasion, compared with speculation refraining, it is more important for these countries to abolish stock transaction tax so as to increase the liquidity of stock market and maintain the neutral tax. Yet, in Chinese market, private investors are in the leading position and plentiful speculative short-term transactions take up the significant market shares. Because most of the short-term transactions are speculations or hassle exchanges based on technical analysis. And their essence is the arbitrage behavior without real transaction demand which is similar to "Zero-sum Game". Generally speaking, short-term transactions will only bring about market volatility and asset bubble instead of increasing actual economic value. More importantly, such meaningless transaction process will waste valuable social resources. Therefore, it is wise for China to combine with the current national and market situation. At the same time, China should properly utilize financial transaction tax system to refrain speculative behaviors on the premise that market liquidity will not be excessively influenced or market efficiency will not be reduced greatly.

\section{Conclusion}

For the forward skeleton of Chinese stock transaction tax legal system, according to the research in this article, the author holds that it is inadvisable to abolish stock transaction tax at present. On the contrary, this system should be further improved.

Firstly, the secondary market stock stamp duty charged currently can be changed as stock transaction tax so as to conform to its essence of tax appellative. Simultaneously, the establishment and modification of securities transaction tax legal system should go by Legislative Law strictly. This is not only the basic requirement of "the rule by law", but also the fundamental guarantee for tax-payers rights and interests.

And in terms of the tax system design, combining with the problems that Swedish stock transaction tax collection had, Chinese stock transaction tax legal system design may attempt to bring as many stock transactions related to China in overseas markets as possible into tax scope in the future. Or it will bring such alternative markets geographically close to mainland as Hong Kong into tax scope during the major trend that mainland may further open its connective stock mechanism. In the meantime, the stock transaction tax system should try to adopt wider tax base so as to include various trading tools and refrain investors from transforming trading forms to avoid tax.

In the end, it is advisable to collect stock transaction tax aimed at secondary market and collect stamp duty aimed at the conclusion of contracts or property rights transfer documents at the primary market at the same time In this way, we can avoid the unfair phenomenon that the primary market of mainland stock market has high profit but low tax compared with secondary market. And the earning gap between primary and secondary markets can be lessened by means of transaction ax. That can better stimulate corporate to focus on internal management and long-term development rather than raise money simply by listing.

\section{References}

Keynes, J. M. (1936). The General Theory of Employment, Interest, and Money. London: Macmillan Cambridge University Press.

Liu, J. W. (2007). Financial and tax law. Law Press China.

Rao, L. X. (2009). Study in Chinese stamp-tax. Doctoral dissertation.

Schulmeister, S., Schratzenstaller, M., \& Peck, O. (2008). A General Financial Transactions Tax: Motives, Revenues, Feasibility, and Effects. (Vienna: OsterreichischesInstitut fur Wirtschaftsforschung (WIFO)).

Shi, C. C., \& Fan, X. L. (2004). Theory of Securities Transaction Tax and Development of Its Practice. Finance \& Trade Economics, 5.

Tan, J. J. (2006). The Volatility of Securities Transaction Tax and Security Market. Academic Forum, 8. 
Zhang, S. W. (2012). Theories of taxation law. Peking University Press.

http://china.huanqiu.com/News/mofcom/2014-11/5220406.html

http://finance.sina.com.cn/stock/usstock/c/20140715/105619708236.shtml

http://www.csrc.gov.cn/pub/newsite/zjhxwfb/xwdd/201411/t20141114_263377.html

\section{Copyrights}

Copyright for this article is retained by the author(s), with first publication rights granted to the journal.

This is an open-access article distributed under the terms and conditions of the Creative Commons Attribution license (http://creativecommons.org/licenses/by/3.0/). 